\title{
Improved Model for Predicting Annulus Pressure Drop during Underbalanced Drilling
}

\author{
Fadairo Adesina Samson ${ }^{1 *}$, Adeyemi Gbadegesin', Bello Kelani² and Olafuyi Olalekan² \\ ${ }^{1}$ Department of Petroleum Engineering, Covenant University Ota, Nigeria \\ ${ }^{2}$ Department of Petroleum Engineering, University of Benin, Nigeria
}

\begin{abstract}
Most time during underbalanced drilling or cleaning of well, formation fluid (oil and water) influx is usually experienced as soon as productive zone is penetrated because formation pore pressure gradient are higher than hydrostatic pressure gradient. Successful flow of fine drilling cuttings and formation fluid (gas, oil and water) to the surface flow facilities therefore demands for accurate prediction of pressure drop along the well bore during underbalanced drilling. Previous studies on pressure profile prediction in the wellbore during underbalanced drilling have not taken into account the effect of cuttings volume. The purpose of this study is therefore to develop an improved model that predicts the effect of cuttings volume on annulus pressure drop in the wellbore during underbalanced drilling. This is an extension of Guo and Fadairo model for investigating the effect of cutting volume pressure drop during underbalanced drilling. The result of the study shows that the cutting flow rate increases with small pressure differential while it decreases with large pressure differential. This depicts that cutting retards fluid flow and increases bottom-hole pressure and fluid density, resulting in low fluid velocity and cutting lifting capacity of the drilling fluid. This may result in cutting accumulation, ultimately reducing the ability of the drilling fluid to effectively lift drill cuttings from bottom-hole to the surface and eventually lead into stuck drilling string.
\end{abstract}

Keywords: Underbalanced; Drilling; Cutting volume; Pressure drop; Model

\section{Introduction}

When a well is drilled underbalanced, hydrocarbon production begins as soon as productive zone is penetrated $[1,2]$. It is possible to produce portion of the reservoir fluid while drilling or cleaning the hole. With suitable processing equipments, some underbalanced wells may pay for their cost entirely from production before drilling operations were completed $[1,2]$. The technique requires the simultaneous flow of fine drilling cuttings and formation fluid (gas, oil and water). If the pressure profile in an underbalanced well can be predicted within reasonable accuracy, it would be possible to get good estimates of the power required to lift the accumulated cutting and formation liquid while drilling or cleaning the hole. Furthermore, the effect of injection rate, cutting transport and annulus sizes on these quantities can be evaluated before any design decision is made on the drilling, hole cleaning and operation of the flow string.

Studies [1-5] on simultaneous flow of fine drilling cuttings and formation fluid influx (gas, oil and water) in vertical pipe has sought to develop a technique with which the pressure drop can be accurately calculated. A lot of research has been conducted to model the flow of fluids in pipes and its corresponding pressure drop [6-8] but little information has been reported on the effect of cuttings transport on pressure drop and cutting hold up along the vertical pipe. Fadairo [2] and Nguyen [5] presented the application of multiphase flow modelling to underbalanced drilling which was considered a key tool for the underbalanced drilling engineer to identify the bottom-hole pressure [1,5]. Guo [4] presented three analytical models that are coded in a spreadsheet program to simulate solid, water, oil, and gas flow in underbalanced drilling and the pressure drop was predicted [1]. Nguyen [5] formulated a model that coupled underbalanced well bore pressure distribution with the productivity parameters [5] while Fadairo [2] presented a methodology which used a single phase flow model to simulate multiphase fluid flow system and the key factors that influence the pressure drop during underbalanced drilling were identified [1].

The study present a comprehensive model for predicting pressure drop and describing the detrimental effect of drill cutting hold-up on fluid flow along the vertical pipe in underbalanced drilling. The validation of this improved model with Guo [1] model as reported in Tabatabei [6] paper shows that inclusion of cutting volume and all pressure dependence parameters such as oil formation factor, water formation factor, gas deviation factor, solution gas in the liquid phase are vital parameters that govern the magnitude of pressure drop along the wellbore while drilling or cleaning underbalanced well.

\section{The model assumptions}

The analytical expressions derived in this study are based on the following fundamental and general assumptions:

1. No mechanical work is performed on the system

2. Temperature of system is assumed constant at some average value

3. Friction is considered and assumed to be constant over the length of the system.

4. Change in kinetic energy is small but is not neglected

*Corresponding author: Fadairo Adesina Samson, Department of Petroleum Engineering, Covenant University Ota, Nigeria, E-mail: adesinafadairo@yahoo.com

Received September 29, 2014; Accepted December 19, 2014; Published January 01, 2015

Citation: Fadairo AS, Adeyemi GA, Kelani B, Olafuyi O (2015) Improved Model for Predicting Annulus Pressure Drop during Underbalanced Drilling. J Pet Environ Biotechnol 6: 203. doi:10.4172/2157-7463.1000203

Copyright: (c) 2015 Fadairo AS, et al. This is an open-access article distributed under the terms of the Creative Commons Attribution License, which permits unrestricted use, distribution, and reproduction in any medium, provided the original author and source are credited. 
5. Steady-state flow of drill cuttings with formation fluid was considered throughout the process.

\section{Model formulation}

Considering the steady-state energy equation for flow in pipes [6,7],

$\frac{144 \Delta P}{\rho_{m}}+\frac{g}{g_{c}} d L+\frac{f u^{2}}{2 g D} d L=0$

Since the difference between $\mathrm{g}$ and $\mathrm{gc}$ is negligible, equation (1) becomes,

$\frac{144 \Delta P}{\rho_{m}}+\left(1+\frac{f u^{2}}{2 g D}\right) d L=0$

Apparent density and viscosity of a multiphase mixture can be defined respectively $[1,2]$.

$$
\begin{aligned}
& \rho_{m}=\rho_{d c} H_{d c}+\rho_{f}\left(1-H_{d c}\right) \\
& \mu_{m}=\left[\mu_{\circ} h_{\circ}+\mu\left(1-h_{\circ}\right)\right] H_{L}+\mu_{g}\left(1-H_{L}\right) \\
& \rho_{f}=\left\lfloor\left[\rho_{\circ} h_{\circ}+\rho_{w} h_{w}\right] H_{L}+\rho_{g}\left(1-H_{L}\right)\right\rfloor\left(1-H_{d c}\right)
\end{aligned}
$$

\section{Drilling cutting density}

The volumetric flow rate of the drill cutting can be expressed as;

$q_{d c}=\frac{Q_{d c}}{86400}$

The density of the drill cutting can be expressed as a ratio of flow rate of the cutting to cutting production rate as expressed by equation (7) [1,5]:

$\rho_{d c}=\frac{W_{d c}}{q_{d c}}=6.24 \frac{\pi}{4}\left(\frac{d_{b}^{2}}{12}\right) S_{d c}\left(\frac{86400 R_{p}}{3600 q_{d c}}\right)$

Converting units of flow rate from $\mathrm{ft} 3$ to gallons, equation (7) becomes,

$$
q_{d c}=\frac{1.0917 d_{b}^{2} S_{d c} R_{p}}{q_{d c}}
$$

\section{Gas density}

Density of gas at a point in a vertical pipe may be obtained from the gas law depending on pressure and temperature and converting from units of $\mathrm{ft} 3$ to gallons;

$$
\rho_{g}=\frac{3.8735 P S_{g}}{Z R T}
$$

\section{Density of the formation fluid}

The density of the formation liquid (oil and water) is obtained as;

$\rho_{L}=\rho_{\mathrm{o}} h_{\circ}+\rho_{w} h_{w}$

And converting from units of $\mathrm{ft} 3$ to gallons

$\rho_{L}=\left(\frac{8.343 S_{\circ}+0.001818 S_{g} R_{s}}{B_{\circ}}\right)$

\section{Density of the mixture}

The density of the mixture is defined as the summation of apparent density of the entire components, simultaneously flowing into the conduit. The density of the mixture is obtained by substituting equations (8), (9) and (11) into equation (3), we therefore express multiphase density as

$$
\rho_{m}=\left\{\left[\left(\frac{8.343 S_{\circ}+0.0018 S_{g} R_{s}}{B_{\circ}}\right) h_{\circ}+\frac{8.343 S_{w} h_{w}}{B_{w}}\right] H_{L}+\frac{3.8735 P S_{g}\left(1-H_{L}\right)}{Z R T}\right\}\left[1-H_{d c}\right]+\left[\frac{1.0917 d_{b}^{2} S_{d c} R_{p}}{q_{d c}}\right] H_{d c}
$$

\section{Velocity of mixture}

The velocity of the multiphase fluid flow at a cross-section of a vertical pipe is defined and shown as [2,3]; 
$U_{M}=\frac{1}{A}\left[q_{g}\left(\frac{14.7}{p}\right)\left(\frac{T}{520}\right)\left(\frac{Z}{I}\right)\left(\frac{144}{86400}\right)+\frac{q_{o} B_{o}(5.615)}{86400}+\frac{q_{w} B_{w}(5.615)}{86400}+\frac{q_{d c}}{86400}\right]$

$U_{M}=\frac{0.00005998 q_{g} T Z}{P D A N^{2}}+\frac{0.000082735 B_{\circ} q_{\circ}}{D A N^{2}}+\frac{0.000082735 B_{w} q_{w}}{D A N^{2}}+\frac{0.00001473 q_{d c}}{D A N^{2}}$

Putting equations (14) and (12) into equation (2)

$\frac{144 \Delta p}{\rho_{m}}=\left[1+\frac{f\left(\frac{0.00005998 q_{g} T Z}{P D A N^{2}}+\frac{0.000082735 B_{\circ} q_{\circ}}{D A N^{2}}+\frac{0.000082735 B_{w} q_{w}}{D A N^{2}}+\frac{0.00001473 q_{d c}}{D A N^{2}}\right)^{2}}{D}\right] d L$

Expanding equation (15) and converting diameter D (inches) to feet, we have;

$\frac{144 \Delta P}{\left\{X H_{L}+\frac{3.874 P S_{g}\left(1-H_{L}\right)}{Z R T}\right\}\left[1-H_{d c}\right]}=\left[1+F_{1}\left(\frac{Z}{P}\right)^{2}+F_{2}\left(\frac{Z}{P}\right) B_{\circ}+F_{3} B_{w}\left(\frac{Z}{P}\right)+F_{4}\left(\frac{Z}{P}\right)+F_{5} B_{\circ}^{2}+F_{6} B_{\circ} B_{w}+F_{7} B_{\circ}+F_{8} B_{w}^{2}+F_{9} B_{w}+F_{10}\right] d L$

Re-arranging equation (16), we have;

$$
\frac{144 \frac{Z}{P} \Delta P}{\left[1+F_{1}\left(\frac{Z}{P}\right)^{2}+F_{2}\left(\frac{Z}{P}\right) B_{\circ}+F_{3} B_{w}\left(\frac{Z}{P}\right)+F_{4}\left(\frac{Z}{P}\right)+F_{5} B_{\circ}^{2}+F_{6} B_{\circ} B_{w}+F_{7} B_{\circ}+F_{8} B_{w}^{2}+F_{9} B_{w}+F_{10}\right]\left\{\left(\frac{q_{d c} X H_{L} T}{0.3610 S_{g}}\right)+\left(\frac{1.0917 d_{b}^{2} S_{g c} R_{p} T H_{r}}{0.3610 S_{g}}\right)+\frac{P}{Z} q_{d c}\left(1-H_{L}\right)\right\}}
$$

and equating the pressure dependent variables to the non-pressure dependent variables, equation (17) becomes;

$$
\begin{aligned}
& 144 \frac{z}{p} \Delta P-\frac{0.361 S_{g} L}{T} \\
& {\left[\frac{q d_{o} X H_{L} T}{0.361 S_{g}}+\frac{p}{Z} q_{d c}\left(1-H_{L}\right)+\left(F_{1}\left(\frac{z}{p}\right)^{2}+F_{2} B_{c}\left(\frac{z}{p}\right)+F_{3} B_{w}\left(\frac{z}{p}\right)+F_{4}\left(\frac{z}{p}\right)+F_{5} B_{c}^{2}+F_{6} B_{0} B_{w}+F_{7} B_{o}+F_{8} B_{w}^{2}+F_{9} B_{w}\right)\left(\frac{q_{d c} X H_{L} T}{0.361 S_{g}}+\frac{1.0917 d_{b}^{2} S_{g} R_{p} T H_{r}}{0.361 S_{g}}+\frac{p}{Z} q_{d c}\left(1-H_{L}\right)\right)+F_{10}\left(\frac{q_{d c} X H_{L} T}{0.361 S_{g}}+\frac{p}{Z} q_{d c}\left(1-H_{L}\right)\right)\right]} \\
& =\left(1.0971 d_{b}^{2} S_{g c} R_{p} H_{r} L\right)\left(1+F_{10}\right) \\
& F_{1}=\frac{1.3913 \times 10^{-5} f_{m} q_{g}^{2} T^{2}}{D A N^{5}} \\
& F_{2}=\frac{3.8382 \times 10^{-5} f_{m} q_{\circ} q_{g} T}{D A N^{5}} \\
& F_{3}=\frac{3.8382 \times 10^{-5} f_{m} q_{W} q_{g} T}{D A N^{5}} \\
& F_{4}=\frac{6.834 \times 10^{-6} f_{m} q_{d c} q_{g} T}{D A N^{5}} \\
& F_{5}=\frac{5.2943 \times 10^{-5} f_{m} q_{\circ} q_{w}}{D A N^{5}} \\
& F_{6}=\frac{5.2943 \times 10^{-5} f_{m} q_{\circ} q_{w}}{D A N^{5}} \\
& F_{7}=\frac{9.426 \times 10^{-6} f_{m} q_{\circ} q_{d c}}{D A N^{5}} \\
& F_{8}=\frac{2.647 \times 10^{-5} f_{m} q_{W}^{2}}{D A N^{5}} \\
& \frac{9.426 \times 10 \quad f_{m} q_{W} q_{d c}}{D A N}
\end{aligned}
$$




$$
\begin{aligned}
& F_{10}=\frac{8.392 \times 10^{-7} f_{m} q_{d c}^{2}}{D A N^{5}} \\
& X=\left[\left(\frac{8.343 S_{\circ}+0.00181 S_{g} R_{s}}{B_{\circ}}\right) h_{\circ}+\frac{8.343 S_{W} h_{W}}{B_{W}}\right]
\end{aligned}
$$

Where;

$$
\begin{aligned}
& h_{\circ}=\frac{q_{\circ}}{q_{\circ}+q_{w}} \\
& h_{w}=1-h_{\circ} \\
& H_{L}=\frac{q_{L}}{q_{L}+q_{g}} \\
& H_{d c}=\frac{q_{d c}}{q_{d c}+q_{L}+q_{g}} \\
& H_{r}=\frac{H_{d c}}{1-H_{d c}} \\
& \text { DAN }=\mathrm{DH}-\mathrm{DP}
\end{aligned}
$$

\section{Model analysis}

This study considered the effect of drill cuttings transport on pressure drop which was unaccounted for in the Guo et al model [1] as reported by Tabatabei [6] in the literature. The difference in the results obtained from this study and that of Guo [1] model has shown that cutting volume has significant effect which cannot be overlooked as opined by the earlier authors.

The Guo [1] model in equation (36) can only be valid if the flow rate of the cutting is less than $5 \%$ of total flow rate., whereas, this is not always the case in real scenario. It may also be realistic if the pipe length is short and all pressure dependant variations can be assumed constant.

The models that predict pressure drop at different depth in the wellbore during underbalanced drilling reported by Guo [1] and the present study are given as equations $36 \& 37$ respectively.

$$
\begin{aligned}
& 144 b\left(p-p_{c s g}\right)+\frac{1-2 b m}{2} \ln \left(\frac{(144 p+m)^{2}+n}{\left(144 p_{c s g}+m\right)^{2}+n}\right)-\frac{m+\frac{b}{c} n-b m^{2}}{\sqrt{n}}\left[\tan ^{-1}\left(\frac{144 p+m}{\sqrt{n}}\right)-\tan ^{-1}\left(\frac{144 p_{c s g}+m}{\sqrt{n}}\right)\right]
\end{aligned}
$$

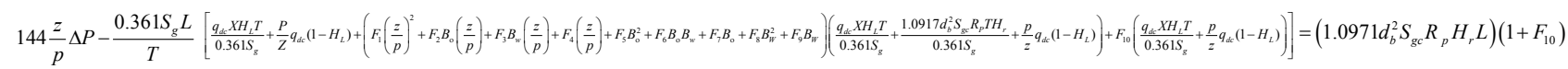

Using the Guo et al data (Table 1) from the literature, the developed model was solved by iteration following the procedure that was presented by Nguyen [5]. The choke pressure (Ps) is known as it is estimated from the surface while the bottom-hole pressure (Pb) is unknown; the point of focus is in this regard. Subtracting the calculated flowing bottom-hole pressure of fluid from that of calculated bottom-hole pressure of cutting and fluid, the pressure drop due to drilling cutting effect is obtained.

This new method is capable of yielding a satisfactory pressure differential result during simultaneous flow of cutting and formation fluids while drilling or cleaning hole. All pressure dependent variables are treated as a function of pressure and not a constant as opined by many investigators.

Figure 1 shows the effect of cutting flow rate on pressure drop in flowing well. The cutting flow rate increases with low pressure differential and decrease with increase in pressure differential. This depicts that cutting retards fluid flow and increases bottom-hole pressure and fluid density, resulting in low fluid velocity and cutting lifting capacity of the drilling fluid. This may result in cutting accumulation, ultimately reduces the ability of the drilling fluid to effectively lift drill cuttings from bottom-hole to the surface and eventually stuck the drilling string. The result also shows that inclusion of cutting volume and all pressure dependence parameters such as oil formation factor, water formation factor, gas deviation factor, solution gas in the liquid phase are vital parameters that govern the magnitude of pressure drop along the wellbore while drilling or cleaning underbalanced well. This evidences that Guo et al. model under-estimated pressure drop along the wellbore while drilling or cleaning underbalanced well for not considering these vital pressure dependence parameters and cutting volume.

\section{Conclusion}

In developing the analytical model, interdependent variables have been thoroughly accounted for to ensure accuracy of the model. Pressure dependent variables were treated as a function of pressure and not constant in order to improve on previous models. The effect of drill cuttings transport was also taken into proper consideration to simulate real flow scenarios. Hence, from the results generated from the analytical model, it 
Citation: Fadairo AS, Adeyemi GA, Kelani B, Olafuyi O (2015) Improved Model for Predicting Annulus Pressure Drop during Underbalanced Drilling J Pet Environ Biotechnol 6: 203. doi:10.4172/2157-7463.1000203

\begin{tabular}{|c|c|}
\hline Surface pressure (psia) & 14.7 \\
\hline Surface temperature (oR) & 60 \\
\hline Oil flow rate (gpm) & 0.000292 \\
\hline Water flow rate (gpm) & 5 \\
\hline Cutting flow rate (gpm) & 0.002896 \\
\hline Bit diameter (in) & 3 \\
\hline Specific gravity of gas & 0.9 \\
\hline Specific gravity of oil & 0.8 \\
\hline Specific gravity of water & 1 \\
\hline Rate of penetration (ft/hr) & 60 \\
\hline Hole Diameter (inch) & 6.5 \\
\hline Drilling pipe diameter (inch) & 3.5 \\
\hline Geothermal Gradient (oF/ft) & 0.01 \\
\hline Drill pipe and casing roughness (in) & 0.0018 \\
\hline Hole Roughness (in) & 0.1 \\
\hline
\end{tabular}

Table 1: Input Data-Fluid, bit, pipe and temperature data.

Source: Guo et al. (2006)

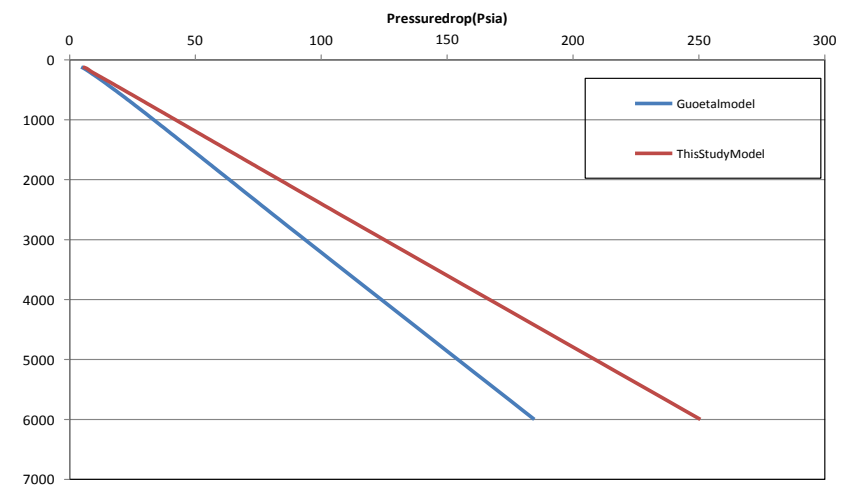

Figure 1: Effect of cuttingvolume on pressuredrop invertical flowingwell. can be concluded that the developed model has led to an improvement in the Guo model in estimating the bottom-hole pressure due to inclusion of cutting volume in the present model.

\section{Recommendation}

Since the inclusion of cutting volume has significant effect on annular pressure drop, the new model is highly recommended and required to accurately predict the vertical wellbore performance and minimum required flow rate for lifting both liquid and cutting during drilling operation essentially in the deep offshore where there is limited source of gas.

\section{References}

1. Boyun, Guo, Ali Ghalambor (2006) A systematic approach to predicting liquid loading in gas wells. Society of Petroleum Engineers.

2. Fadairo AS Adesina, Adekomaya O, Falode O (2009) Effect of drilling cuttings transport on pressure drop in a flowing well. Society of Petroleum Engineers.

3. Adekomaya O, Fadairo Adesina, Falode O (2008) Predictive Tool for Bottomhole Pressure in Multiphase Flowing Wells, Journal of Petroleum and coal 50: $60-66$.

4. Guo Boyun, Yao (2008) Liquid Carrying Capacity of Gas in Underbalanced Drilling, Society of Petroleum Engineers.

5. Nguyen C, Somerville JM, Smart BGD (2009) Predicting the production capacity during Underbalanced Drilling operations in Vietnam, Society of Petroleum Engineers.

6. Tabatabei M, Ghalambor A, Guo B (2008) The minimum required air/ gas injection rate for liquid removal in air/gas drilling, Society of Petroleum Engineers.

7. Butler, Gregory (1995) Multiphase Flow Considerations in Underbalanced Drilling of Horizontal Well, $7^{\text {th }}$ International Conference Multiphase.

8. Sukkar YK, Cornell D (1955) Direct Calculation of Bottom-hole Pressures in Natural Gas wells, Society of Petroleum Engineers 204: 43-48. 